NBFR WORKING PAPER SERIES

THF EFFECT OF JOB COMPLEXITY ON

JOB SATISFACTION: EVIDENCE FROM

TURNOVFR AND ABSENTEEISM

Andrew Veiss

Working Paper No. 1597

NATTONAL BUREAU OF ECONOMIC RESFARCH

1050 Massachusetts Avenue

Cambridge, MA 02138

April 1985

The research reported here is part of the NBER's research program in Labor Studies. Any opinions expressed are those of the author and not those of Bell Communication Research Inc. or of the National Bureau of Economic Research. 


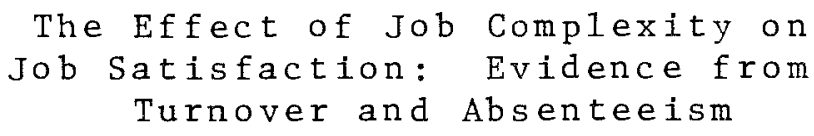

\section{$\underline{A B S T R A C T}$}

Using a detailed sample of semi-skilled production workers we find that holding a wide range of personal and job-related characteristics constant, workers assigned to more complex jobs seem to be more likely to quit than are workers assigned to simpler jobs. Job complexity has no discernible effect on absenteeism. Matching better educated workers to more complex jobs affects neither absenteeism nor quit propensity. Thus it appears that experimental evidence suggesting that job enlargement increases worker satisfaction is likely to stem from the experimental design: asking for volunteers to be assigned more complex jobs, and improving the quality of supervision for workers assigned to more complex jobs.

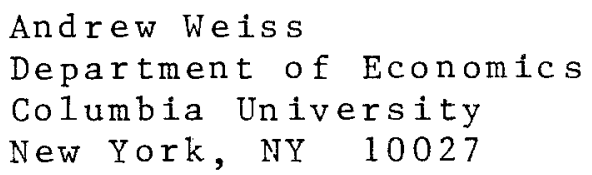




\title{
THE EFFECT OF JOB COMPLEXITY ON JOB SATISFACTION: EVIDENCE FROM TURNOVER AND ABSENTEEISM*
}

\author{
Andrew Weiss
}

Bell Communications Research and Columbia University,

\section{INTRODUCTION}

In recent years, there has been a good deal of attention paid to the effects of job enrichment on labor productivity and job satisfaction. The term job enrichment is used to describe quite different phenomena including:

(a) changing the production mode from an assembly line to work teams each of which assembles a complete product,

(b) giving more responsibility to individual workers, e.g. allowing a worker to stop the assembly line,

(c) increasing the complexity of the task the worker performs.

Some of the productivity improvements claimed from job enrichment are: fewer defects, less absenteeism, and less turnover of workers.

This paper looks at one form of job enrichment - increasing the complexity of manufacturing jobs. I examine the effect of job complexity on the likelihood of a worker quitting and on absenteeism.

Although many recent papers extoll job enrichment as means of increasing job satisfaction and consequently improving worker productivity, reducing quits or improving 
the quality of output, the evidence supporting the benefits of job enrichment is not convincing [see Mitchell Fein, "Job Enrichment Doesn't Work"]. These studies almost invariably relied on screened volunteers so that only the best and most highly motivated were assigned to the "enriched" jobs. The experimenters then discovered, not surprisingly, that the volunteers outperformed the control group.

Two of the most widely cited experiments were conducted by General Foods and Motorola. In the General Foods experiment 63 participants for the experiment were selected from 700 applicants. The selection procedure included five screening interviews. the last interview taking four hours. This experiment seems only to prove that carefully screened workers are likely to perform better than average workers. At Motorola 22 out of 1,200 workers volunteered to individually assemble pocket pagers. Despite the experimenters only using volunteers, and choosing a production item carefully selected to be most amenable to individual assembly, the results in the Motorola experiment were mixed. Management personnel at the plant reported that individual assembly reduced inspection and repair costs but required $25 \%$ more workers. These effects roughly offset one another.

James Hackman points out that managers and consultants who initially argued for the introduction of job enrichment programs are reluctant to report the results of programs that failed. Hackman finds that job enrichment programs are as likely to fail as succeed, but that the successful project are disproportionately represented in published studies.

One study that is not vulnerable to Fein's and Hackman's criticisms is Joel Lefkowitz's investigation of quit rates of sewing machine operators. Lefkowitz obtained a sample of 152 women operators hired at a single plant in 1968 and assigned to jobs of various degrees of complexity. He found that 20 of the 34 workers assigned to the most difficult jobs quit 
within their first 40 work days, while only one of the seven workers assigned to the simplest jobs quit. These data suggest that job complexity is positively related to quit propensity. However, Lefkowitz did not adjust for any other demographic characteristics of the workers, nor did he indicate if the firm randomly assigned workers to jobs of different degrees of complexity. Another difficulty with the Lefkowitz study is that all the workers were paid piece-rate. Although the rates varied across jobs, he did not indicate if average wages differed across jobs. If pay per unit of effort were lower on more complex jobs, this could account for the observed differences in quit rates.

The study I shall describe also explores the effect of job complexity on quit rates. I also look at the effect of job complexity on absenteeism as providing another, albeit weaker, indicator of whether workers prefer more complex or simpler jobs. This study resembles Lefkowitz's in being retrospective (the results were not the product of an experiment) and with being concerned with semi-skilled production workers on similar jobs. My study differs from his in having a much larger sample, roughly equal numbers of men and women, no significant correlation between wages and job complexity or between promotional opportunities and job complexity, and in estimating a structural model of the probability of a worker quitting.

\section{THE DATA}

The data are for 2,920 semi-skilled electronics assembly workers during their first six months of employment. For each worker, the available information includes the number of days the worker was absent, incidents of absenteeism (several consecutive days absent is counted as one incident) as well as whether or not the worker quit, and the date a quit occurred. For many of the workers I also obtained data on the complexity of the job the worker was assigned to, the worker's sex, age, race, years of education, marital status, 
whether or not he was employed when he applied to work for the firm, and his score on the Crawford Physical Dexterity Test. ${ }^{1}$ The workers were hired in either 1977 or 1979 to perform semi-skilled production work at one of three manufacturing facilities. In each location all entry level production workers were on the same pay schedule, regardless of the complexity of the job to which they were assigned, their age, schooling or previous experience. Workers were assigned randomly to jobs by the personnel office. Job assignments were independent of worker characteristics. Although all applicants took the Crawford Physical Dexterity Test, the scores were only used as a hiring criterion: test scores did not influence job assignments. (This test was almost the sole criterion used in hiring workers.) Once a worker was hired he received the base rate pay until his performance exceeded $65 \%$ of expected output for his job - output above that rate was rewarded according to a nonlinear piece rate schedule. This pay schedule was termed "early pay." Once $83 \%$ of expected output was reached for a fiscal month, the worker was assigned to a pay group, almost all workers achieved this level within their first 3 months on the job. All members of a pay group received the same pay, based on the output of the group. This pay averaged $21 \%$ above the base rate. Groups were large, averaging 126 participants, and included workers with a wide range of jobs. (In general, pay groups correspond to product lines.) Within a plant pay differences across groups were trivial. Finally, a worker on early pay could not earn more than the pay of a member of his prospective pay group.

Industrial engineers estimated the number of weeks it should take an average worker to

1. Although both men and women were represented in the sample, I use "he" and "his" when referring to a representative worker. I recognize the sexist implications of those word choices but am not nimble enough to avoid them without lapsing into especially stilted language. 
learn each task to which workers were assigned. I used the logarithm of the training duration of the job to represent job complexity. Since the aim of the study was to measure the effect of job enrichment on workers in a particular plant, rather than the impact on the economy if all firms adopted a job enrichment program, I did not attempt to correct for sample selection bias. ${ }^{2}$

In addition to being exceptionally detailed and well-documented, this data is unique in other respects. First, we are only considering quits of newly hired workers. Previous studies that included tenure as a right hand variable suffer from serious simultaneous equation biases. To see the form this bias takes, let us denote a worker's tenure by $t$, and let $Q$ be a variable which is 1 if the worker quits and zero otherwise. $X$ denotes a vector of observable variables which affect both $t$ and $Q$. Assume $t=X \beta+u_{1}$ and

(1) $Q=\left\{\begin{array}{l}1 \\ 0\end{array}\right.$ if $X \gamma_{1}+t \gamma_{2}>\mu_{2}$ where $\mu_{1}$ and $\mu_{2}$ are random variables.

If equation (1) is estimated without correcting for simultaneous equation bias, then from the tenure relationship independent variables in the quit equation that are correlated with tenure are also correlated with $\mu_{1}$. Since $\mu_{1}$ and $\mu_{2}$ are also correlated (unobserved variables that lead individuals to have more tenure on their job than expected would also lead them to be less likely to quit) and since all elements of $X$ are likely to be correlated with tenure, they are also correlated with $\mu_{2}$ and their estimated coefficients are biased. Consequently estimated coefficients of (1) may lead a researcher to conclude that some

2. The sample may not be representative of the population as a whole since we only have data on workers who both applied to one of the plants and were accepted. On the other hand, the wages and benefits the firm offered induced long queues of applicants for these jobs. Hiring from that queue was almost random, only $22 \%$ of the applicants considered were rejected. Approximately $85 \%$ of rejections were due to poor scores on the physical dexterity test. We corrected for that source of bias in the analysis. 
trait is positively (negatively) correlated with quit propensity when its true correlation is negative (positive). Because the same characteristics affect both tenure and quit propensity, a system of equations that estimated both sets of coefficients simultaneously or through an instrumental variable procedure would only be identified through differences in the functional form of the two relationships. To the extent that unobserved variables that affect absenteeism affect tenure (workers who are often absent will be more likely to be fired and hence will have less tenure) these simultaneous equation biases also arise when attendance is the dependent variable. By restricting the study to newly-hired workers, simultaneous equation biases arising from tenure differences are avoided.

Unfortunately, simultaneous equation bias persists to the extent that other variables. such as age, are correlated with the error term in the quit equation. This bias arises since older workers who are taking a new job are less representative of their age cohort than are younger workers who are taking a new job. Consequently, age is likely to be negatively correlated with the error term in the quit equation causing the estimated coefficient on age to be biased upward: older workers who are starting a new job are likely to have unobserved attributes that increase their quit propensity. The coefficients of variables that are correlated with age are also biased. However, this bias is likely to be small relative to the bias introduced by tenure differences. In addition, because workers are assigned randomly to jobs, any correlation between independent variables in the selection equation and job complexity would be due solely to chance. In the plants being studied, job assignments are made by the personnel office strictly by ranking applicants who have satisfied the hiring criteria (achieved acceptable scores on the dexterity test) in the order in which they applied for work and then assigning them to the available jobs in that order: the $n^{\text {th }}$ applicant (who passes the dexterity test) gets the $n^{\text {th }}$ available job. Similarly, job transfers are made strictly by seniority. This automatic assignment procedure is done in 
order to avoid job discrimination suits or union grievances. The plants are unionized and the unions closely monitor job assignments. The random assignment of individuals to jobs removes another potential source of bias. If job assignments were made on the basis of attributes for which we do not have data, but which are correlated with either absenteeism or quit propensity, our estimated coefficients would be biased.

\section{EMPIRICAL FINDINGS}

Perhaps the best measure of job satisfaction is whether or not the worker quit Isee Nicholson, Brown and Chadwick-Jones]. Since the lifetime earnings for all the workers in our samples would be the same if they did not change jobs, and is independent of job complexity, it seems likely that quit propensity is negatively related to job satisfaction. Consequently, I used quit propensity as a proxy for job dissatisfaction. I estimated the effect of job complexity upon quit rates using a probit model. ${ }^{3}$

A worker quits if and only if

$$
U(A O)-M>U(P J)
$$

where $U(A O)$ represent the utility derived from some alternative job offer, $U(P J)$ represents the utility derived from the worker's present job, $M$ denotes mobility costs.

Let $U(A O)$ and $U(P J)$ each be functions of observed characteristics of the person or the job, denoted by $X$, and error terms, $\eta_{i}$, which capture unobserved job or person related characteristics.

3. Workers who were laid off before completing their first six months on the job were excluded from the sample as were all workers who were hired after any worker who was laid off - each of those workers would have been laid off if they had not quit. Layoffs are determined solely by seniority. 


$$
\begin{aligned}
& U(A O)=f\left(X_{1} \beta_{1}\right)+\eta_{1} \\
& U(P J)=g\left(X_{2} \beta_{2}\right)+\eta_{2}
\end{aligned}
$$

Thus a worker quits his job if and only if

$$
\begin{aligned}
& f\left(X_{1} \beta_{1}\right)-g\left(X_{2} \beta_{2}\right)-M>\eta_{2}-\eta_{1} \\
& \eta_{2}-\eta_{1}-N\left(O, \sigma^{2}\right)
\end{aligned}
$$

I assume that workers are risk neutral, have fixed retirement ages, and that holding age fixed employed women expect to work $25 \%$ fewer hours than employed men. I let $f\left(X_{1}, \beta_{1}\right)$ and $g\left(X_{2}, \beta_{2}\right)$ have the same functional form

$$
f\left(X_{i} \beta_{i}\right)=\int_{0}^{(65-a g e)(1-.25 \text { female })} e^{-\rho t} X_{i} \beta_{i} d t
$$

$\rho$ incorporates both the time preferences of workers, and their projected growth of real wages. Hence if workers discount the future by an amount greater than their anticipated growth of real wages $\rho$ is positive. I estimated the quit equation below using values of $\rho=+.05$ and $\rho=-.05$.

Because we are interested in the effect of job complexity on job satisfaction, job complexity is included as an element of $X$. Integrating (5) and substituting into (4), a worker quits his job if and only if

$$
\begin{gathered}
{[h \text { (age, sex) }]\left[X_{3} \beta_{3}\right]-M>\eta_{2}-\eta_{1} .} \\
\text { where } h(\text { age, sex })=\frac{e^{-\rho\lfloor 1-.25 \text { female }][65-\text { age }]}}{-\rho} .
\end{gathered}
$$

$X_{3}=\left\{X_{1}, X_{2}\right\}$ and includes education, age, race, sex, whether the worker was employed when be applied for the job question, and scores on each section of the Crawford Physical Dexterity Test, as well job complexity. I also included a term measuring the interaction of 
job complexity and education. The interaction effect was calculated as [In (training duration) - mean (In (training duration))] times [education - mean (education)], where the means were calculated separately for each location. This interaction term captures the effect on job satisfaction of matching the better educated workers to the more complex jobs. Although the results reproduced below are derived from equations which included these interaction effects, omitting the interaction effects did not significantly affect the coefficients on the logarithm of job complexity in the various behavioral equations.

Data was available on all these independent variables for 1532 newly-hired workers at two locations, one in the midwest the other in the south. At the third location considerable data was missing and promotional opportunities were correlated with job assignments. Hence we omitted that data in studying quit rates. The median training duration of the jobs to which workers were assigned was seven weeks. The elements of $M$ included marital status, and education.

The other independent variables included in the estimates of the probability of a worker quitting were high school graduation, college graduation, marital status, and education, as well as $h($ age, sex) times : education, age, sex, race, plant locations, whether the worker was employed when he applied to work at the plant, and scores on the physical dexterity test. In the southern location whites were more likely to quit than non-whites (a " $t$ " statistic of 4.25 for $\rho=-.05)$ and workers who were employed when they applied for these jobs and high school graduates were each less likely to quit (" $t$ " statistics of -4.45 and -1.97 respectively for $\rho=-.05)$. None of the other independent variables were statistically significant. 
Insert Table 1 about here

To gain some intuition about the economic significance of these results for $\rho=-.05$; a one standard deviation increases in $h(\cdot) \times \operatorname{Ln}$ (training required) increases the probability of a worker quitting within the first 6 months on these jobs by $2.2 \%$ when all independent variables are assigned their mean values. Since only $12.27 \%$ of the workers in the sample quit within their first six months on the job, this is an economically as well as statistically significant result.

Before concluding from these observations that increasing job complexity decreases job satisfaction $\mathrm{I}$ investigated the partial correlation between job complexity and absenteeism. The reported linkages between absenteeism and job satisfaction is weaker than between quits and job satisfaction. Consequently, I did not expect to find a strong relationship between absenteeism and job complexity. The investigation of the relationship between absenteeism and job complexity was a check on the earlier results. A significant positive correlation would cost considerable doubt on the conclusion from the study of quit ratesthat workers dislike more complex jobs.

Absenteeism was measured in two ways: incidents of absenteeism and days absent. Regardless of the measure used the effect of job complexity on absenteeism was not statistically significant. Because there are few large studies of absenteeism I have listed the estimated coefficients of all the independent variables. (For the estimates listed below data from all three locations was used, the results were not significantly altered if the third plant was omitted).

In estimating the effect of job complexity and the interaction between education and job 
complexity on occasions absent I used the negative binomial procedure described in Hausman, Hall and Griliches (1981). This procedure assumes that the occasions of absenteeism for each individual is generated by a Poisson arrival process. The individual specific parameters $\lambda_{i}$ are assumed to have a gamma distribution across the population. I assumed $\lambda$ was a linear function of job complexity (the logarithm of the number of weeks required to learn the assigned job) and the interaction of education and job complexity as well as age, sex, race, geographic location, previous employment status, education, high school graduation, college graduation, scores on the dexterity test. The sample was limited to people who worked for the firm for at least six months.

Insert Table 2 about here

I used the same independent variable to estimate the percentage of days a worker was absent during his first six months on the job. Those observations were weighted by the square root of the number of days worked, and a Tobit estimation procedure was used.

Insert Table 3 about here

As can be seen, job complexity seems uncorrelated with occasions absent and is either uncorrelated or negatively correlated with the percentage of days absent. This evidence supports our tentative conclusion from the data on quits: job satisfaction is not greater on more complex jobs. 


\section{CONCLUSION}

The evidence we have presented suggests that if job enrichment takes the form of increasing the complexity of semi-skilled production jobs (job enlargement), the job satisfaction of workers is likely to fall. The principal measure of job satisfaction used was quit propensity. This empirical evidence accords with the casual observation that job enrichment programs are invariably initiated by management not by workers or unions. The data presented contradicts various experimental findings. However, those experiments relied on volunteers - it is not surprising that while randomly selected workers seem to prefer simpler jobs, workers who ask to be reassigned to more complex jobs prefer the jobs they requested. 


\section{REFERENCES}

Fein, Mitchell, "Job Enrichment Doesn't Work," Atlanta Economic Review," Vol. 25, No. 6, 1975, pp. 55-54.

Hackman, J. Richard, "On the Coming Demise of Job Enrichment," Technical Report No. 9, Department of Administrative Sciences, Yale University, 1974.

Hausman, Jerry, Bronwyn Hall and Zvi Griliches, "Econometrics Models for Count Data with an Application to the Patents - R\&D Relationship," unpublished mimeo, 1981.

Joel Lefkowitz, "The Effects of Training on the Productivity and Tenure of Sewing Machine Operators," Journal of Applied Psychology, Vol. 54, No. 1, 1970, pp.81-85.

Nicholson, N., Brown, C. A. and Chadwick-Jones,J. K., "Absence from Work and Job Satisfaction," Journal of Applied Psychology, Vol. 61 (Dec. 1976): 728737. 
TABLE 1

\section{Effect of Job Complexity on Quit \\ Rates Within 1st Six Months on the Job}

(" $t$ " statistics in Parentheses)

\begin{tabular}{|c|c|c|c|c|}
\hline & Coefficient & $\begin{array}{l}=-.05 \\
\Delta \text { in Quit Rate } \\
\text { at Quit Rate }=.10\end{array}$ & Coefficient & $\begin{array}{l}\rho=.05 \\
\Delta \text { in Quit Rate } \\
\text { at Quit Rate }=.10\end{array}$ \\
\hline Ln (Training Reqd.) & $\begin{array}{c}.00973 \\
(2.31)\end{array}$ & .027 & $\begin{array}{r}.0015 \\
(2.64)\end{array}$ & .0267 \\
\hline $\begin{array}{l}\text { Interaction between Education } \\
\text { and } \operatorname{Ln} \text { (Training Reqd.) }\end{array}$ & $\begin{array}{r}-.0038 \\
(-1.21)\end{array}$ & -.012 & $\begin{array}{l}-.0068 \\
(-1.52)\end{array}$ & .012 \\
\hline Proportion of Quits within 6 months & .123 & & & \\
\hline Number of Observations & 1532 & & & \\
\hline Log likelihood & -525.18 & & -530.34 & \\
\hline
\end{tabular}

* Data on race was not available for the southwest location. 


\section{TABLE 2}

Occasions Absent in 1st Six Months on the Job Negative Binomial Estimation Procedure

(" $t$ " statistics in parentheses)

\begin{tabular}{|c|c|}
\hline Ln(Training Reqd) & $\begin{array}{c}\text { Coefficient } \\
-.00106 \\
(-.028)\end{array}$ \\
\hline $\begin{array}{l}\text { Interaction between Education } \\
\text { and Ln(Training Reqd) }\end{array}$ & $\begin{array}{l}.011 \\
(.350)\end{array}$ \\
\hline Intercept & $\begin{array}{c}2.86 \\
(5.58)\end{array}$ \\
\hline Age & $\begin{array}{r}-.035 \\
(-9.20)\end{array}$ \\
\hline Male & $\begin{array}{l}-.114 \\
(-2.09)\end{array}$ \\
\hline White $\times$ South & $\begin{array}{r}.535 \\
(5.51)\end{array}$ \\
\hline White $\times$ Midwest & $\begin{array}{c}-.11 \\
(-1.61)\end{array}$ \\
\hline South & $\begin{array}{r}-.285 \\
(-2.72)\end{array}$ \\
\hline Employed at Application & $\begin{array}{r}-.137 \\
(2.79)\end{array}$ \\
\hline Married & $\begin{array}{l}.0085 \\
(.17)\end{array}$ \\
\hline Southwest* & $\begin{array}{r}.384 \\
(4.14)\end{array}$ \\
\hline H.S. graduate & $\begin{array}{r}-.239 \\
(-2.59)\end{array}$ \\
\hline College Graduate & $\begin{array}{l}.028 \\
(.112)\end{array}$ \\
\hline Education & $\begin{array}{c}.44 \\
(1.43)\end{array}$ \\
\hline Dexterity Test Score & $\begin{array}{l}.0034 \\
(.69)\end{array}$ \\
\hline Intercept & $\begin{array}{c}2.86 \\
(5.58)\end{array}$ \\
\hline Number of Observations & 1565 \\
\hline Log Likelihood & -1333.51 \\
\hline Mean Occasions Absent & 1.41 \\
\hline
\end{tabular}


TABLE 3

\section{Percentage of Days Absent in 1st Six}

Months on the Job*

(" $t$ " statistics below coefficient)

\begin{tabular}{|c|c|c|}
\hline Variable & Coefficient & $\begin{array}{c}\text { Effect of a one } \\
\text { standard deviation } \\
\text { change on the percentage } \\
\text { of days absent }\end{array}$ \\
\hline Ln(Training Reqd) & $\begin{array}{l}-.197 \\
(.97)\end{array}$ & -.13 \\
\hline $\begin{array}{l}\text { Interaction between } \\
\text { Ln(Training Reqd) and Education }\end{array}$ & $\begin{array}{l}-.079 \\
(-.54)\end{array}$ & -.06 \\
\hline Intercept & $\begin{array}{r}.641 \\
(3.03)\end{array}$ & \\
\hline Age & $\begin{array}{c}-.12 \\
(-7.48)\end{array}$ & -.90 \\
\hline Male & $\begin{array}{r}-.751 \\
(-2.57)\end{array}$ & \\
\hline White $\times$ South & $\begin{array}{l}1.96 \\
(3.72)\end{array}$ & \\
\hline White $\times$ Midwest & $\begin{array}{c}-.166 \\
(-.454)\end{array}$ & \\
\hline South & $\begin{array}{c}-2.85 \\
(-4.96)\end{array}$ & \\
\hline Southwest & $\begin{array}{r}.749 \\
(1.37)\end{array}$ & \\
\hline H.S. graduate & $\begin{array}{c}-1.572 \\
(-3.41)\end{array}$ & \\
\hline College Graduate & $\begin{array}{l}-1.087 \\
(-.77)\end{array}$ & \\
\hline Education & $\begin{array}{l}.132 \\
(.77)\end{array}$ & \\
\hline Dexterity Test Score & $\begin{array}{l}-.013 \\
(-.47)\end{array}$ & \\
\hline Employed at Application & $\begin{array}{r}-.962 \\
(-3.67)\end{array}$ & \\
\hline Married & $\begin{array}{l}-.053 \\
(.21)\end{array}$ & \\
\hline Number of Observations & 1840 & \\
\hline
\end{tabular}

Number of Observations

* The coefficients were estimated using a tobit estimation procedure-each observation was weighted by the square root of the number of days worked. The mean value of percentage of days absent was 2.71 .

** The computations in the third column are the effects of changes in the independent variables (not multiplied by the weighing factor) on the percentage of days absent. 